One School's Approach to the Additional Area of Science Requirement for Civil Engineering

Dr. Robert Hamilton P.E., Boise State University

Dr. Hamilton has been with Boise State University since 1995, where he helped found the Civil Engineering Department. 


\title{
One School's Approach to the Additional Area of Science Requirement for Civil Engineering
}

\begin{abstract}
In 2008 ABET's Engineering Accreditation Commission (EAC), the body responsible for accreditation of engineering programs, changed the criteria for Civil Engineering programs to include a requirement that graduates of those programs "can ... apply knowledge of . . . at least one additional area of science, consistent with the program educational objectives". ${ }^{1}$ This new requirement appears to have its origins in the Body of Knowledge (BOK), and the desire to make those ideals and the ABET requirements for Civil Engineering programs become one in the same. However, for many programs across the country this became an issue of concern and confusion. Taking its cue from the BOK the "one additional area of science" shortly became defined to mean a physical science, as opposed to a social science, and that this "area of science" could not include Computer Science, Chemistry or Physics.
\end{abstract}

Because of this, programs needed to change their curricula to address this criterion. Schools that had an emphasis where additional Chemistry or Physics courses had previously been incorporated to take advantage of native strengths in their university or to support the focus of their program now had to reassess the value of these course versus the need to cover an area of science outside these fields. Many other schools had not required a science course outside of Chemistry or Physics and now needed to add a course to address this issue. Still others who may have required such a course now needed to assess the effectiveness of yet another course taught outside their department.

This paper will look at the method adopted by one university to meet this new criterion while at the same time attempting to remain true to the goals and objective of that program with respect to providing a broad education to its students and utilizing the unique and distinct opportunities that program's university provided to those same students. This university adopted the use of a questionnaire given to all students who graduated with the criterion of an additional "area of science" included in their graduation requirements to collect data on the subject. The questionnaire asked which area of emphasis within Civil Engineering the student planned to pursue upon graduation, which additional "area of science" the student the student studied while they were in school, and how this additional "area of science" aided them in their understanding of Civil Engineering.

The results obtained, after this new criterion had been in effect for several years offers insight into both the method of meeting this requirement chosen by this university, as well as comments on the benefit of this criterion for the Civil Engineering profession as a whole.

\section{Introduction}

With the change in accreditation requirements for Civil Engineering programs in the 2008-09 ABET criteria there arose a point of confusion and concern on the part of several Civil Engineering programs around the country. In the 2008-09 criteria, under the Program Criteria for Civil and Similarly Named Engineering Programs a requirement was introduced calling for 
"at least one additional area of science, consistent with the program educational objectives". 1 Through secondary sources ${ }^{2}$, various meeting and word of mouth it was relatively quickly determine that this additional area of science must be a physical science thus excluding computer science and the social sciences, and that it could not include in-depth studies in either physics or chemistry. The reasoning behind the creation of this new criterion is addressed in the text titled Civil Engineering Body of Knowledge for the $21^{\text {st }}$ Century, Second Edition (BOK2) ${ }^{3}$. This text, while not the criteria for accreditation of Civil Engineering programs is seen as a statement of where the professions should be going in its educational endeavors.

With the addition of a new criterion the level of rigor for achievement of this criterion was another question that needed to be addressed. Some programs had already required science courses but had not analyzed what the students learned in these courses. Other programs had science courses as prerequisites for certain engineering courses. Many programs had not specified an additional science course in their degree requirements. In addition many schools were beginning to experience crowding in these very same science courses as the number of students increased due to the poor economy and the push for more STEM majors both hit at the same time. All of these programs would need to address this new criterion in some manner.

This paper will look at the approach taken by one school, and the data collected over a four-year span, to address this new criterion. This paper will not attempt to present a universal solution for dealing with this new criterion, nor will it compare what has been done at other schools with our approach.

\section{Our Approach}

When the faculty at our university looked at this new criterion we found ourselves in the group of programs that did not currently include an additional area of science in our degree requirements. Conventional wisdom, as well as anecdotal data suggests that students do not select their area of specialization until their senior year. ${ }^{4}$ When we looked at our students, we found individuals who were not sure which specialization they wished to pursue until their senior year, once they had completed the majority of their course work and possibly had served an internship (which is not required for graduation). We also saw students who shifted back and forth on what area of civil engineering they wanted to study in more depth. Up until this point we had tried to create an atmosphere that allowed our students to explore many different aspect of the profession, and we valued this ability to choose very highly. Part of this choice came in not requiring too many, usually not more than one, courses in any one specialization. The students were then free to select elective courses they felt would be appropriate for their chosen field. This was a trait of our program we very much wanted to continue.

Our solution to this issue was to add a Science Elective to the list of required courses, which in turn reduced the number of engineering courses the students were required to complete for their degree. Students were allowed to select courses from a list of preapproved science courses primarily in the area of Biological or Environmental Sciences and the area of Geosciences. Some of the preapproved courses were lower division courses such as Fundamentals of Geology or General Biology. Other courses were junior or senior level courses such as Water Supply and Water Quality Management or Applied Geophysics. Our method of assessment was to develop a 
questionnaire which is to be filled out by the students in their final semester. The data collected in this questionnaire is then reduced and distributed to the faculty for review. None of the preapproved science courses are prerequisite to any engineering courses. While this method of assessment is indirect in nature, it did allow us to gain a feel for our student population and what they were looking for in an engineering education. 5,6

Because a student may graduate with the degree requirements that are in place at the time they enroll in the university many of our graduates during the four school years when data has been collected for this paper were not required to meet this new criterion. As the years progress the number of students required to meet this criterion increases resulting in a more encompassing set of results compared to the graduating class as a whole. It should also be noted that while many of our students graduate at the end of the spring term, historically we have had a large percentage of our students complete their degrees and graduate in December or in the summer. As a result the data displayed in Table 1 references a school year running roughly from August to July.

\begin{tabular}{|c|c|c|c|}
\hline School year & $\begin{array}{c}\text { Number of } \\
\text { Graduates }\end{array}$ & $\begin{array}{c}\text { Number of } \\
\text { students taking a } \\
\text { Science Elective }\end{array}$ & $\begin{array}{c}\text { \% of graduates } \\
\text { taking a Science } \\
\text { Elective }\end{array}$ \\
\hline $2010-2011$ & 42 & 6 & $14 \%$ \\
\hline $2011-2012$ & 34 & 12 & $35 \%$ \\
\hline $2012-2013$ & 52 & 28 & $54 \%$ \\
\hline $2013-2014$ & 40 & 40 & $100 \%$ \\
\hline
\end{tabular}

Table 1 - Students fulfilling this requirement

\section{Questionnaire}

The choice of the questionnaire as the tool to gather data for assessment was one based upon practicality. Since no single course had been specified, and since the time within the curriculum for students to take their additional science course was far from uniform it was felt that the only method to obtain data from all students was by questionnaire.

Originally the questionnaire consisted of five questions, but on review by the faculty question four was reworked to yield more specific information. The questions used are as follows:

1. What science course did you take?

2. What area of Civil Engineering do you plan to/would you like to specialize in?

3. How did the science course help your understanding of your chosen specialization?

4. Did you take your science course before taking the entry level (300 level) engineering course in your specialization? (Y/N)

a) If you took your science course before taking the 300 level engineering courses did the science course influence your specialization in Civil Engineering? 
b) If you took your science course after taking the 300 level engineering courses did the science course change your mind concerning your specialization in Civil Engineering?

5. How and where have you been able to apply what you learned in your science course?

\section{Results of the Questionnaire}

When looking at the results of the surveys it may be seen that the students have tended to take a random and even distribution of courses based upon field of interest. The first question asked which specific science course the student took to fulfill this requirement. The data collected then grouped the courses into three categories of Basic Biology (such as Introduction to Biology), Basic Geology (such as Fundamentals of Geology) and Other (courses that did not fall into the prior two categories, such as Environmental Geology).

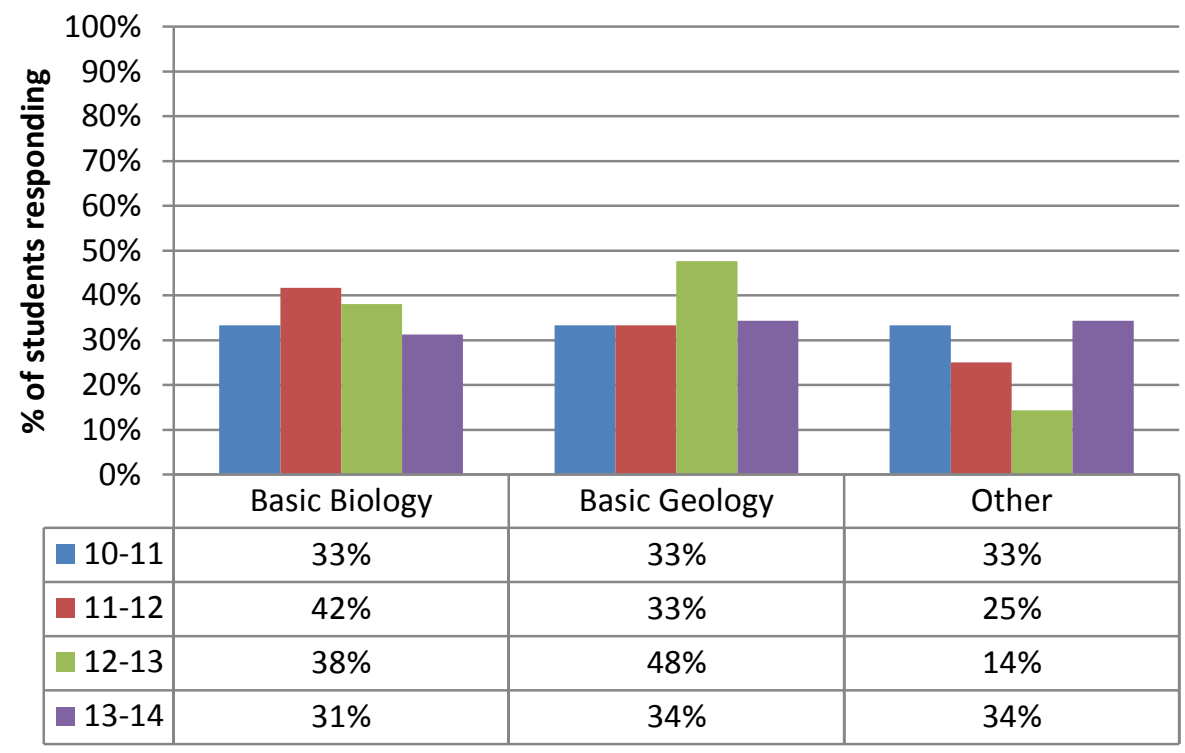

Figure 1 - Science Elective field

The second question asked the students what branch or branches of Civil Engineering the student wished to pursue upon graduation. While most selected a specific discipline many students expressed the idea that they were interested in working across disciplines. Our university offers courses in a number of areas of Civil Engineering, but primarily focuses on five branches. The results of this question imply that approximately $40 \%$ of the students would be interested in a biological science to aid their understanding of their chosen field (Environmental and Water Resources emphases) and the other 60\% (Structural, Geotechnical, Transportation) would be interested in a geoscience. 


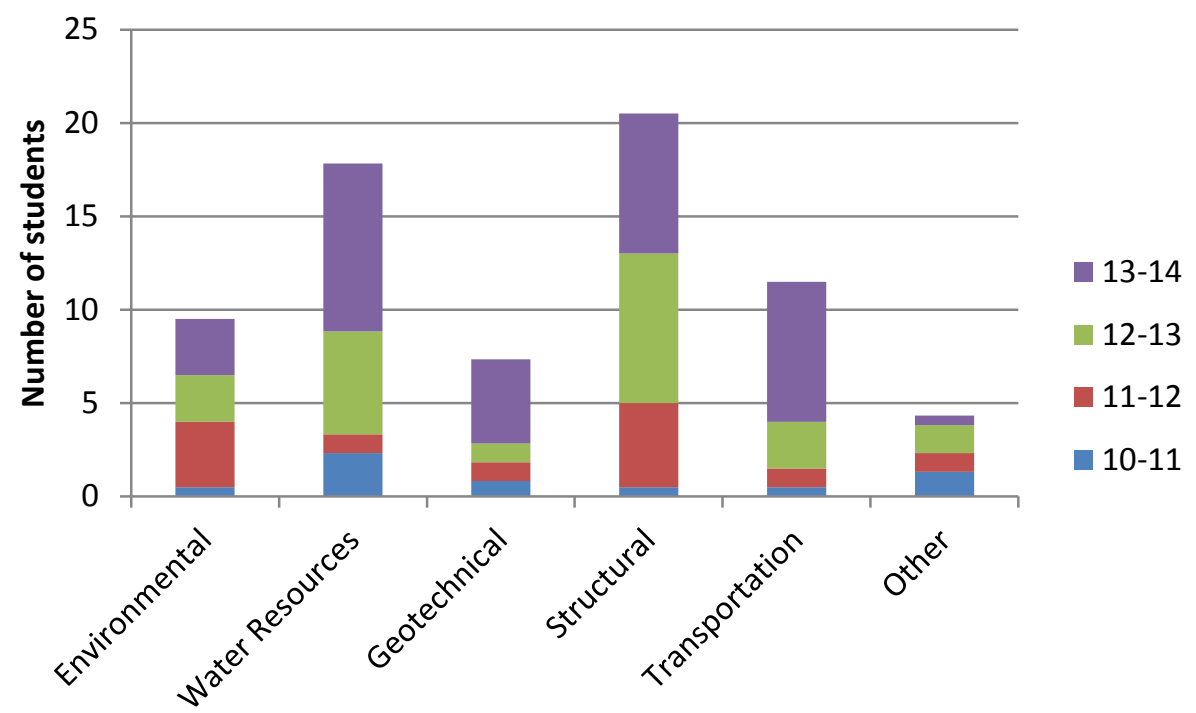

Figure 2 - Civil Engineering field

Question three dealt with the relevance of the science course with respect to the student's choice of specialization. Approximately half of the respondents felt that their choice of science course did help them understand their chosen field.

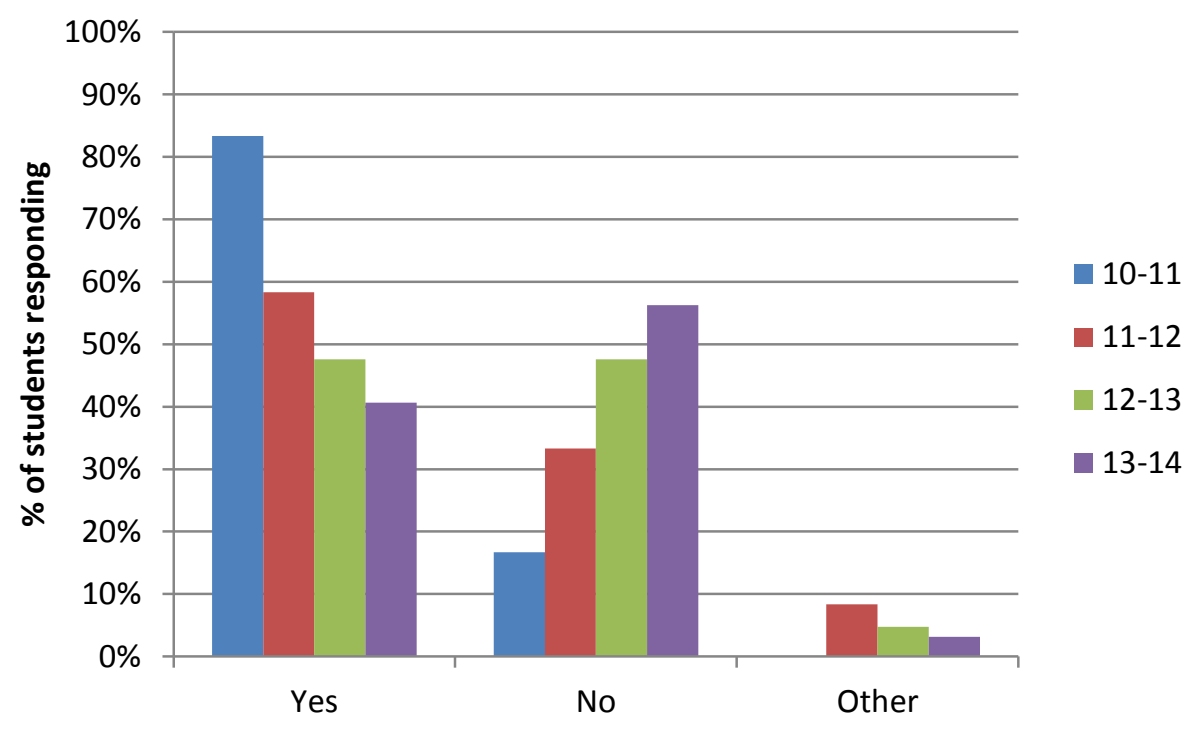

Figure 3 - Aid in understanding

Question four is in fact two questions. The first questions deals with when the students took the science elective in their academic careers. It is advised that the students take this course late in their academic careers so that they can make an informed decision about what course would be most useful to them and their chosen specialization. However, due to the fact that many if not most of our students transfer courses to our university we felt a significant number of students may have already have taken an approved science course before joining us. Therefore the first 
part of this question was asking when students had taken their science elective, before or after they were juniors in our program.

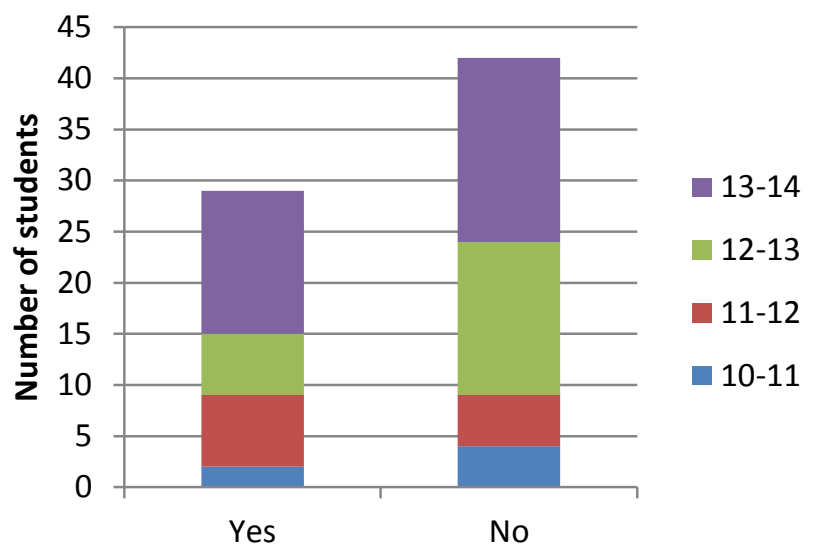

Figure 4 - Was the Science Elective taken prior to the Junior Year?

As can be seen in Figure 4 approximately $30 \%$ of the students responding had taken their science course prior to taking the junior level Civil Engineering courses or in other words prior to having a significant amount of information to make an informed decision.

The second portion of the fourth question asked if the science elective had influenced the student's choice of specialization. This portion of the question was added the second year of the survey, so no data is available for the 2010-2011 school year.

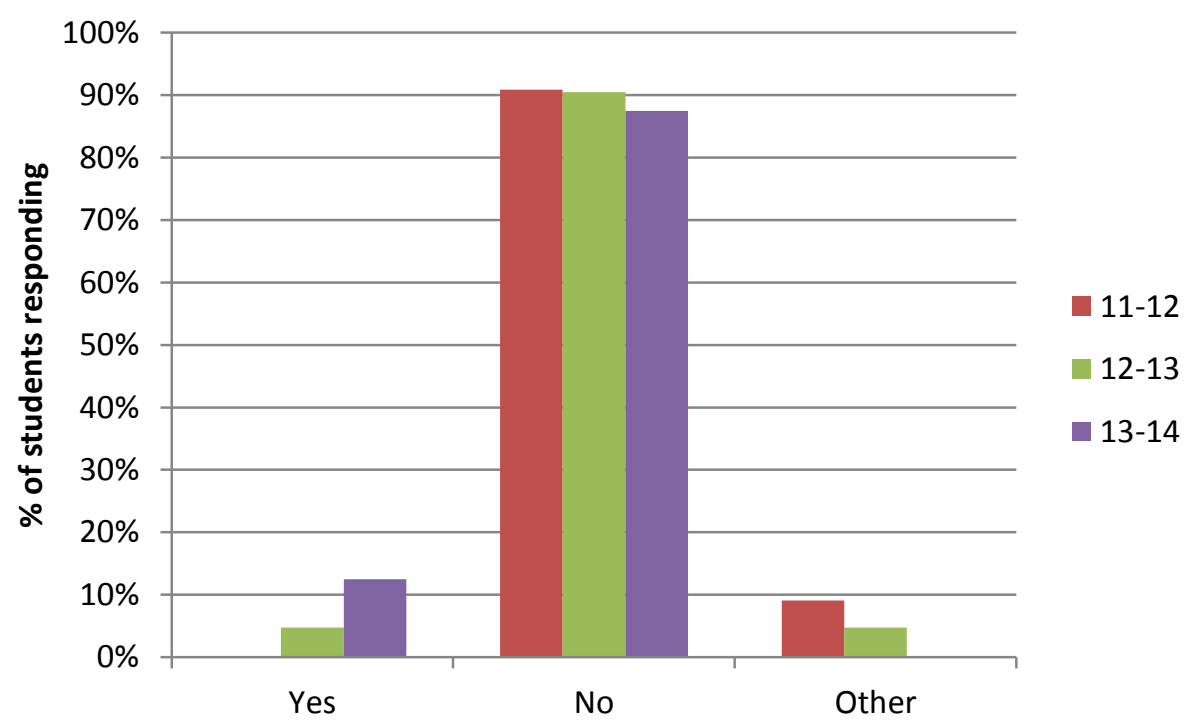

Figure 5 - Influence of Science Elective on Specialization Selection 
Figure 5 includes students who took their science elective both prior to their junior year and those who took the course during or after their junior year. It is clearly seen that the science elective had almost no effect on the choice of specialization the students chose.

The final question asked if the students felt that they had been able to use the information from their Science Elective. The results of this question have been broken down into three groups.

1. The students who felt they have gained useful information and/or insights from their science elective that they have been able to use in school.

2. They student who felt that they have not been able to use information obtained from their additional science course.

3. Students who felt that they had gained insights or useful information, but have been able to apply it outside of the classroom only.

From Figure 6 it may be seen that the largest group feel that they have been able to apply information in the classroom, but it should be noted that as the number of respondents has increased this perception is shifting. In the last two years of the study, the two years with the largest populations, the majority of students responded that they felt the information gained was not of use in the classroom.

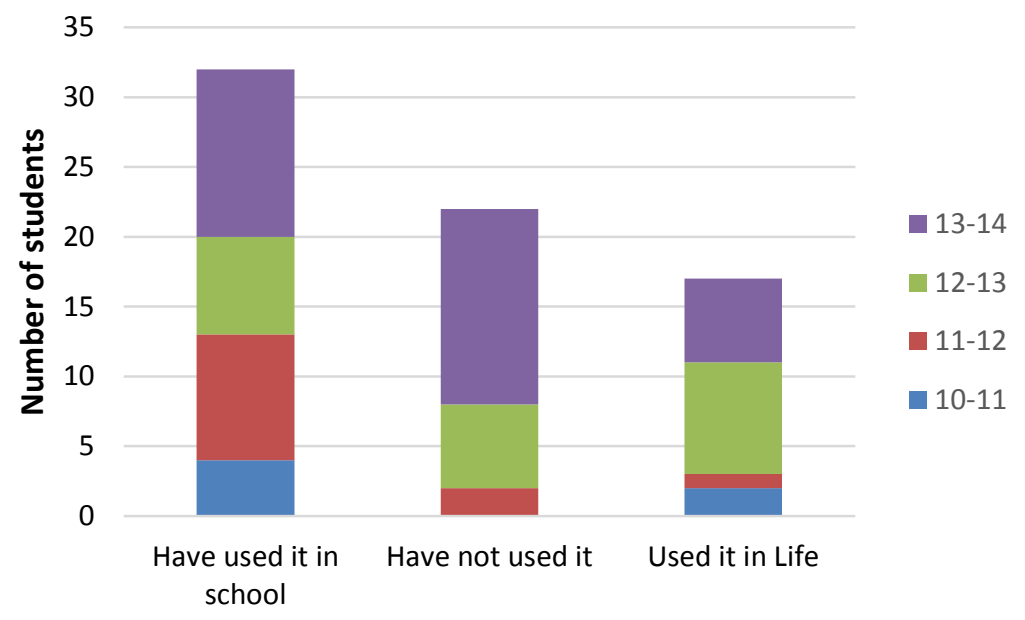

Figure 6 - Use of content/concepts

\section{$\underline{\text { Results: }}$}

The results of this study show that our students have divided themselves approximately evenly between the biological and life sciences and the geosciences when choosing a science course. This in turn approximates their selection of specialization within Civil Engineering. Approximately half of the students felt that the science course they did select did in fact help them in their understanding of their chosen specialization while at the same time almost none of them felt that the science course affected their choice of specialization regardless of when they took the science course. However, it must be noted that as the percentage of graduates required to meet this criterion increases the trend concerning how helpful the course was to understanding their specialization appears to be decreasing. 
Approximately $60 \%$ of our students took their science course during or after their junior year in college. Of the $40 \%$ who took their science course prior to this many had transferred this credit to our university, some from high school. It is unclear if this was to support their choice of specialization or if this influenced their choice, although the students themselves denied the latter. This early selection, especially among those who transferred their credits, may be tied to lack of choices available to them at the time. This large percentage taking their science course this early may lead to issues of students feeling they wasted this opportunity by taking a course in a field other than what would support their specialization.

Finally, about $45 \%$ of our students have been able to use some information gained through their science elective at some point in their engineering education. An additional $24 \%$ felt that the information gained was useful not in school, but in their lives.

\section{Conclusion:}

When given a choice the students will take courses that support their goals and add to their understanding of their chosen specialization. The science elective does not seem to influence which specialization that will be, although further study of those taking science courses for credit while still in high school may be warranted. The majority of students feel that they gained useful knowledge in their science elective that aids them both in their scholarly activities as well as helping them be well rounded in life.

Some trends in the data such as the reduction in the aid to understanding of their specialization will need to continue to be monitored. There is also an apparent contradiction between if their science elective has aided them in understanding their chosen specialization compared to if they have been able to use the information gained in their science elective. These questions may need to be refined.

\section{References}

1. Accreditation Board for Engineering and Technology (ABET). (2008). 2008-2009 Criteria for Accrediting Engineering Programs, Retrieved May 31, 2008 from http://www.abet.org/

2. American Society of Civil Engineers (2008).COMMENTARY For Civil and Similarly Named Engineering Programs Draft of January 2008. Retrieved May 31, 2008 from http://www.asce.org/

3. American Society of Civil Engineers (2008). Civil Engineering Body of Knowledge for the $21^{\text {st }}$ Century: Preparing the Civil Engineer for the Future (second ed.), Reston, VA.

4. "When and how exactly do you choose your subdiscipline". Retrieved April 1, 2015 from http://www.reddit.com/r/EngineeringStudents/comments/ 
5. Besterfield-Sacre, M., Atman, C. J. and Shuman, L. J. (1998), Engineering Student Attitudes Assessment. Journal of Engineering Education, 87: 133-141. doi: 10.1002/j.2168-9830.1998.tb00333.x

6. Puerzer, R. J. and Rooney, D. M. (2002), The Alumni Survey as an Effective Assessment Tool for Small Engineering Programs. Journal of Engineering Education, 91: 109-116. doi: 10.1002/j.2168-

9830.2002.tb00679.x

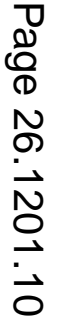

